\title{
Relaciones laborales, conflicto y proceso de producción en la industria del cemento, Olavarría, 1940-1970
}

\author{
Griselda Lemiez ${ }^{1}$ \\ Universidad Nacional del Centro \\ de la Provincia de Buenos Aires/ CONICET \\ griseldalemiez@hotmail.com
}

\section{Resumen}

El siguiente trabajo tiene como objetivo analizar las relaciones laborales construidas en torno al proceso de producción de las industrias cementeras de la ciudad de Olavarría. Partiremos de conflictos laborales, ocurridos en tres empresas, tomando los expedientes judiciales que detallan, entre otras cosas, las causas $\mathrm{y}$ formas que adoptaron dichos conflictos. Consideramos de fundamental importancia, rescatar el valor de las fuentes judiciales y de sus aportes para el estudio de ciertas conductas obreras y patronales, en relación a las pautas disciplinarias aplicadas por la empresa.

Palabras Clave: Relaciones laborales - Expediente judicial - Disciplina laboral

\begin{abstract}
This study focuses on the significance to analyze the relations built around the process of producing cement industries of the city of Olavarría. Based on labour disputes arising at three companies, the research centres on the court records which describe in detail, among other things, the causes and forms adopted by such dispute. We consider the recovery of the value of judicial sources of the utmost importance as well as their respective contributions to the study of some types of labour-management behavior associated with disciplinary directives applied by the company.
\end{abstract}

Key Words: Labour relations - Court records - Labour discipline

1 Becaria Doctoral del CONICET.

LEMIEZ, Griselda, "Relaciones laborales, conflicto y proceso de producción en la industria del cemento, Olavarría, 1940-1970", en Avances del Cesor, Año X, $\mathrm{N}^{\circ} 10$, 2013, pp. 227-247. 


\section{Introducción}

El siguiente trabajo, pretende analizar las relaciones laborales construidas en torno al proceso de producción de las industrias cementeras de la ciudad de Olavarría._Hemos seleccionado tres empresas: la Compañía Argentina de Cemento Portland Sierras Bayas S.A., la Compañía Industrial Argentina Loma Negra S.A. y la fábrica Calera Avellaneda S.A., que se encuentran ubicadas en la zona serrana del Partido de Olavarría y que se dedican a la producción de cal y cemento. Partiremos de la observación de una selección de expedientes judiciales, con el objetivo de responder algunos de los interrogantes que surgen a partir de los vínculos que unían a los trabajadores y los nexos generados con la empresa, durante el período 1940-1970. Luego del análisis específico de dichos expedientes, en correspondencia con las relaciones laborales construidas en la industria del cemento, pasaremos a centrarnos en visualizar las formas en que se expresaba dicha relación, a partir de los actores que entraban en juego, en este caso los trabajadores del cemento y sus superiores. ${ }^{2}$ Los elemento que aparecen como parte de sus discursos, que recrean situaciones que involucran a los individuos que analizaremos, serán retomados para interpretar los efectos de las relaciones laborales en el proceso de producción industrial. ${ }^{3}$

Consideramos que la información que este material nos brinda, permitirá evidenciar la forma en que se manifestaron las estrategias empresariales y discursivas, como una manera de generar el vínculo de pertenencia con la empresa y mantener una determinada disciplina y estabilidad laboral. De este modo, se pretende enfatizar en las relaciones establecidas en el interior de este tipo de industria, y específicamente en las problemáticas que aparecen en el proceso de producción, vinculadas a los conflictos que surgían entre los empleados, iniciados por diversos motivos, ya sea por discusiones del momento, por desacuerdos en la forma del manejo de una máquina o por malos tratos de las capataces hacia los trabajadores.

2 En estas empresas el personal en general tiene como superiores a: a) Sub-capataces-capataz b) Jefe de sección c) Superintendente, debiendo tener presente en todas las actuaciones referentes a sus tareas el citado cuadro jerárquico y todos los pedidos, reclamos, etc., se deberán elevarlos en conformidad al orden del mismo.

3 Dichos expedientes, forman parte del corpus de causas correccionales del Juzgado de Paz de la ciudad de Olavarría y la indagación en torno a dichos expedientes estará fundamentada en la idea que afirma que por medio de las fuentes judiciales podemos ingresar a un mundo lleno de imágenes, donde aparecen individuos interactuando, recreando situaciones de una sociedad dinámica y en transición, donde también encontramos un proceso de interrelaciones, que atraviesa a distintos sectores sociales, que los comunica y los relaciona en el complejo transcurso de reconstrucción de los procesos históricos. Estos impresos están "organizado[s] para ser leído[s] y comprendido[s] por numerosas personas; intenta[n] anunciar y crear un pensamiento, modificar un estado de las cosas con la exposición de un historia o una reflexión.” En FARGE, Arlette, La atracción de archivo, Edicions Alfons El Magnanim, Valencia, 1989, p. 10. 
Los aspectos que desarrollaremos en este artículo, se vinculan con la forma en que se despliega en estas empresas la relación laboral, donde aparece el conflicto en cuestiones que se relacionan directamente con el proceso de producción. Para ello, trataremos de ver como se expresa el conflicto en la práctica, considerando su significado para las estructuras sociales, de las cuales forma parte. Nos interesa ver como la conducta, en el lugar de trabajo, gana un significado muy particular que puede relacionarse a una noción de conflicto, por lo tanto creemos interesante comprender como adquiere una forma particular en determinados ambientes. Nos preguntaremos por qué los trabajadores responden con diferentes conductas y para ello prestaremos atención a las circunstancias particulares a las que están sujetos. ${ }^{4}$ Creemos que es de fundamental importancia tener presente que los conflictos industriales pueden expresarse de diversas maneras, que incluyen un amplio número de conductas que van más allá de las tradicionalmente conocidas, como el sabotaje, ausentismo, accidentes, huelgas, entre otras. De esta forma, partiendo del origen de los conflicto dentro del proceso de producción, trataremos de ver como adquiere en las empresas un significado particular, para los actores que se ven involucrados en dicho contexto.

El lugar donde se enmarcan las relaciones laborales que analizaremos, configura un sistema de fábrica con villa obrera, como entramado particular de relaciones sociales en los espacios urbanos dominados por una gran empresa. Allí, las condiciones de trabajo aparecen limitando y determinando en gran medida las formas de vida y las relaciones extralaborales, muchas veces diluidas en los enfoques centrado en la dimensión representacional o simbólica. Esto quiere decir que, más allá de las representaciones que los trabajadores construyeron de la relación laboral, existió un fuerte condicionamiento de la villa obrera, propiedad de la empresa, donde dichas imágenes se entremezclaban, vinculando las relaciones laborales con las relaciones de la vida cotidiana, que se sintetizaban en la construcción de la imagen de una "gran familia" empresarial. El trabajo de José Sergio Leite Lopes ${ }^{5}$ retomado por el análisis de Federico Neiburg ${ }^{6}$ para el caso de las empresas cementeras ubicadas en el centro de la provincia de Buenos Aires, traza un punto de partida en los análisis que proponen reflexionar sobre esta temática específica.

La predominancia de establecimientos fabriles en la zona serrana próxima a la ciudad de Olavarría, imprimió rasgos muy singulares a la organización del trabajo. ${ }^{7} \mathrm{~A}$ partir de la

4 EDWARDS P. K. y SCULLION Hugh, La organización social del conflicto industrial. Control y resistencia en el lugar de trabajo, Blackwell, Basil, 1982, p. 7.

5 LEITE LOPES, José Sergio, El vapor del diablo. El trabajo de los obreros del azúcar, Colección Estudios de Antropología del Trabajo, Antropofagia, Buenos Aires, 2011, p. 9.

6 NEIBURG, Federico, Fábrica y Villa Obrera: Historia social y antropológica de los obreros del cemento, Centro Editor de América Latina S.A., Buenos Aires, 1988.

7 "La producción de cemento portland comienza a desarrollarse en esta ciudad en el año 1917, con la instalación de la Compañía Argentina de Cemento Portland en Sierras Bayas, la primera empresa en 
fecha que estas empresas se instalan en la ciudad, y de ahí en adelante, la actividad minera se convierte en la principal actividad económica, dado el gran porcentaje de trabajadores que se incorporaron al sistema productivo. Sobre el proceso de producción concreto de la industria del cemento, puede decirse que las demandas permanentes de fijación de la mano de obra, delimitaron la aplicación de una forma de gestión empresarial, que se vinculaba directamente con la necesidad de consolidar un mercado de trabajo. Las estrategias que utilizaron los empleadores para lograr y mantener un control sobre el lugar de trabajo, estuvieron acompañadas de la posibilidad de aparición de distintos tipos de resistencia por parte de los trabajadores. El objetivo del siguiente trabajo será visualizar las características y las formas de las relaciones laborales en la producción cementera durante el período seleccionado, enfatizando en determinadas conductas que registran los expedientes, que alteraron el orden y la disciplina que se buscaba instaurar, y que se expresaron en fuertes agresiones por parte de los trabajadores a los capataces de estas empresas.

\section{El modelo de gestión empresarial}

Para comprender la configuración de este tipo de relaciones laborales, desplegadas en las industrias cementeras, resulta imprescindible tener presente el espacio donde se llevaba a la práctica, es decir, el sistema de fábrica con villa obrera y las características del proceso de producción que lo regían. Atendiendo a esta cuestión y antes de comenzar con el análisis de la configuración de este modelo de gestión empresarial, retomaremos y describiremos brevemente la relación entre el mismo y la inmigración. Debemos recordar que para el año 1920, la inmigración cumplió el papel destacado en la conformación de la fuerza de trabajo de la actividad minera dado que la antigua forma de producción, envasado, distribución y comercialización del cemento, requería gran cantidad de mano de obra, que además debía residir cerca de las fábricas debido a las características del ciclo continuo de producción del cemento. Las fábricas, debían estar cerca de las canteras, dadas la materia prima que utilizaban y las características del proceso de producción implementado. Al escaso desarrollo

poner en marcha un horno horizontal, una innovación que habría transformado la industria a finales del siglo XIX. En la fábrica trabajaban 200 obreros para los que se habían construido un conjunto de viviendas que pronto se transformó en una villa obrera. que junto con las particularidades del medio natural y la especificidad de la producción, diseñaron una compleja trama de situaciones que marcaron un sistema de funcionamiento singular. El éxito de la primera empresa moderna y la disponibilidad de caliza y arcilla incentivaron nuevas inversiones. En el año 1926 fue inaugurada la primera planta de Loma Negra S.A., propiedad del terrateniente Alfredo Fortabat, la primera empresa de capital argentino que utilizó una tecnología de producción continua. Por último, en el año 1932 se suma a estas empresas cementeras Calera Avellaneda S.A., que se embarcó en la elaboración del cemento con las más modernas tecnologías de su tiempo". En BELINI Claudio, La industria peronista: 1946-1955 políticas públicas y cambio estructural, Edhasa, Buenos Aires, 2009, p. 177. 
de tecnología vinculado al transporte y a la infraestructura de caminos, se sumaba la problemática de la inestabilidad de la mano de obra necesaria para la producción. ${ }^{8} \mathrm{La}$ urgencia de contar con la permanencia de la misma era evidente y dada las ventajas económicas y socioculturales otorgadas por las posibilidades laborales que ofrecía la Argentina, posibilitaron que llegaran trabajadores desde diversos países. De esta manera, el nacimiento de las denominadas villas obreras, levantadas en los alrededores de la ciudad, casi a la sombra de cada fábrica, fue el resultado de la necesidad de contar con un mercado de trabajo estable.

La importancia de la zona en cuanto a sus posibilidades productivas, ha constituido un referente para el desarrollo regional, especialmente para el Partido de Olavarría. Con la llegada de los inmigrantes, la transformación del espacio social dio lugar a la aparición de nuevos ámbitos de relaciones e intercambios de experiencias. Por otra parte, la llegada de una gran masa de mano de obra con escasa o nula calificación laboral, hizo necesaria la aplicación por parte de las empresas de una estrategia de gestión formativa, donde los mecanismos de control no fueron siempre tan directos. Nace, de esta manera, una política de corte paternalista, adoptada por gran parte de las empresas de la región, que desplegaron mecanismos similares al momento de llevarlos a la práctica. El reclutamiento de los trabajadores, pasó a ser una prioridad, al momento de la necesaria incorporación de la mano de obra al proceso de producción. El carácter migratorio de los trabajadores por un lado y la función que cumplía el reclutamiento y las modalidades de contratación por el otro, desempeñaron un rol central dentro del sistema de fábrica con villa obrera. Las diversas formas que fue adoptando y expresando el proceso de constitución y posterior consolidación de un mercado de trabajo, encontraron una estrecha relación con las características del proceso de producción utilizado por las empresas cementeras en la ciudad de Olavarría. Ante la necesidad de contar con la mano de obra destinada a la producción, se crearon mecanismos o estrategias empresariales que facilitaron la llegada de inmigrantes, que se incorporaron al sistema productivo. Posteriormente, la formación de esta mano de obra y los medios para buscar la fijación de la misma, estuvieron estrechamente unidos a la aplicación de la política en un espacio constituido como un sistema donde la empresa y la vida cotidiana de los trabajadores quedaban estrechamente ligadas. En síntesis, las características específicas del proceso de producción de cemento, que demandaban la permanente fijación de la mano de obra, delimitaron la implementación de una forma de gestión empresarial, que se vinculaba directamente con la consolidación de un mercado de trabajo.

Para comprender las similitudes y diferencias que encontramos entre estas tres plantas industriales ubicadas en la zona serrana de la ciudad de Olavarría, realizaremos un breve análisis de cada una de ellas, en relación a las características de la estructura de producción. Comenzaremos por la Compañía Argentina de Cemento Portland Sierras Bayas S.A. Esta planta, producía cemento portland conocido en el comercio con la designación de

Diario El Popular de Olavarría, Edición especial, 1899-1999, p. 13. 
Cemento San Martín, de alta resistencia inicial destacado comercialmente con el nombre de Incor. La materia prima utilizada para la producción estaba constituida por dos materiales básicos: la piedra caliza y la arcilla común. ${ }^{9}$ La proporción media en que se encontraban ambos constituyentes era la siguiente: caliza $51,92 \%$ y arcilla ordinaria $48.08 \%$. El procedimiento empleado en la trituración y pulverización de la materia prima, en Sierras Bayas, era progresivo. Se contaba con dos trituradoras. Una de ellas se hallaba instalada bajo un tinglado y su personal trabajaba al amparo del mismo o al aire libre. La segunda trituradora estaba dentro de un galpón y la atención de su personal era circunstancial. La molienda se efectuaba en los molinos instalados en el interior de un galpón y el material se secaba en un secador rotativo, operado por un foguista y un ayudante. El procedimiento empleado en la obtención de la mezcla, se llevaba adelante cuando el material secado era pulverizado. La molienda se realizaba en dos tipos de molinos. En el primero, se obtenía la finura de molienda correspondiente y en el otro se conseguía la segunda finura necesaria para pasar a la cocción. Para este procedimiento se usaba un modelo de horno de tipo rotativo de carga mecánica. La temperatura máxima en la zona de fusión era de 1600 grados y para eso se utilizaba como combustible fuel-oil y como sustitutos, quebracho y vegetales. Los hornos rotativos se hallaban instalados bajo tinglado, al tiempo que las bocas de descarga de los hornos y enfriadores estaban instalados en un galpón. El procedimiento de carga, descarga y selección de clinker ${ }^{10}$ se efectuaba mecánicamente. El transporte se realizaba por medio de un túnel de bajo nivel y la cinta transportadora se cargaba automáticamente por gravitación y estaba vigilada por un solo operario. La trituración y pulverizaron del clinker se realizaba en el primer molino y el yeso previamente molido se mezclaba automáticamente y se pulverizaba. Terminada la operación de la molienda, las partículas del material cocido pasaban a través de un tamiz. En Sierras Bayas no existía operación de cernido, y el embolsado se efectuaba automáticamente, las máquinas se encontraban en el interior de un galpón provisto de grandes aberturas y el personal destinado a esta tarea debía utilizar obligatoriamente máscaras protectoras.

La Compañía Industrial Argentina Loma Negra S.A. elaboraba cemento portland co-

9 VACCAREZZA, Rodolfo, Higiene y Salubridad en la Industria del Cemento Portland. Su investigación en las fábricas argentinas, Asociación de fabricantes de cemento portland, Buenos Aires, 1950.

10 "La caliza cocida, es la definición más exacta de lo que se conoce como clinker, la principal materia prima de la que se obtiene el cemento. Previamente, el clinker es sometido a un proceso de cocción, a partir del cual puede ser utilizado por las industrias que lo someterán a una trituración laboriosa de la que se obtiene el cemento. Para ello, los operarios de las fábricas de cemento emplean unos molinillos especiales en los que se muele directamente el clinker, que está constituido por una especie de bolas de color grisáceo de tamaño similar al diámetro de una pelota de golf, aunque en ocasiones son más pequeñas". En http://www.diariosur.es/prensa/20060809/malaga/clinker_20060809. html Fecha de Consulta: 2 de mayo de 2012. 
nocido en el comercio bajo el nombre de Loma Negra y extraía además de sus canteras granito y granullo. Como materia prima para la elaboración del cemento se empleaba la piedra caliza, arcilla común, oxido de hierro y yeso. El procedimiento de trituración se efectuaba bajo tinglado y era progresivo, el cual producía el desprendimiento de gran cantidad de polvo. Previa pulverización en molinos giratorios provistos de bolas de acero en su interior, la mezcla se efectuaba por vía húmeda, es decir que en este caso como parte del proceso de producción se añade agua. Luego se procedía a la cocción en hornos rotativos a una temperatura que oscilaba entre los 1400 y 1600 grados. Como combustible se utilizaba únicamente fuel-oil. Los hornos estaban bajo tinglados que poseían extractores de aire. El procedimiento de carga y descarga del clinker era automático en Loma Negra y el transporte se realizaba por intermedio de elevadores. El ambiente en esta sección era muy caluroso y la presencia de polvo era permanente. El clinker era triturado y pulverizado en molinos a bolsas y el $90 \%$ de las partículas pasaban a través de un tamiz. En esta fábrica, el cernido tenía lugar a través de filtros de succión y este procedimiento se realizaba también para la recuperación de los polvos. El embolsado se realizaba bajo tinglado en máquinas automáticas, donde cada obrero manejaba tres bocas.

Por último, la fábrica Calera Avellaneda S.A. producía cemento portland, conocido comercialmente con el nombre de Avellaneda. La materia prima empleada por esta fábrica -al igual que en la anterior- estaba constituida por piedra caliza, arcilla común, oxido de hierro y yeso. En el procedimiento de trituración se utilizaban dos operaciones, una primaria y otra secundaria. En la primera se trituraba a cono, introduciendo las piedras en una máquina que reducía el tamaño de las mismas, y en la segunda, mediante trabajo manual que finalizaba con el proceso de reducción del tamaño de las piedras extraídas de la cantera. El personal trabajaba bajo tinglado y en el procedimiento utilizado para obtener la mezcla, la molienda, se efectuaba por medio de molinos giratorios con bolas de acero en su interior. Este procedimiento se conoce con el nombre de vía seca. En la cocción el modelo de horno utilizado en esta fábrica era el rotativo y su temperatura era similar al de las otras dos fábricas. El combustible empleado era el fuel-oil y el carbón mineral. Los hornos se hallaban instalados en un local abierto y la temperatura elevada en esta sección se veía neutralizada en sus efectos por el bajo porcentaje de humedad y el poder refrigerante del aire, aún cuando el movimiento del mismo era excesivo. En cuanto al procedimiento de carga y descarga del clinker, se efectuaba por medio de elevadores y transportadores que funcionaban automáticamente, sin intervención directa del personal. El transporte hacia el depósito se realizaba por medio de una grúa eléctrica y desde los depósitos a los silos de reserva, el clinker era transportado a los molinos mediante una grúa eléctrica a cinta transportadora sin-fin. En esta fábrica no se realizaba operación alguna de cernido y el embolsado se efectuaba automáticamente por procedimiento mecánico, donde cada obrero manejaba tres bocas. El local donde estaba instalada la embolsadora era cerrado, con ventanas y puertas.

Pese a las similitudes que encontramos en el proceso de producción desplegado por estas tres empresas cementeras, vemos que aparecen diferencias, principalmente en las formas y 
las condiciones de producción. La principal diferencia era la ubicación de las maquinarias, es decir si el personal se encontraba bajo techo o trabajaba al aire libre. La predominancia de estos establecimientos fabriles en la zona serrana próxima a Olavarría, fue imprimiendo rasgos muy singulares a la organización del trabajo, que junto con las particularidades del medio natural y la especificidad de la producción, componían una compleja trama de situaciones que marcaban un sistema de funcionamiento singular.

\section{El análisis de las relaciones laborales a través de los expedientes judiciales}

Es en el análisis de los expedientes judiciales, donde encontramos una descripción detallada de ciertos conflictos ocurridos en el lugar de trabajo, que involucraron a los empleados de las empresas cementeras, y que finalizaron en agresiones verbales y físicas. Son estos episodios los que nos permiten replantearnos algunos aspectos de la relación laboral desplegada, que vinculaba a los operarios entre sí y los relacionaba con quienes ocupaban cargos jerárquicos en la empresa.

Podemos ver, por ejemplo como un abogado que representaba a la compañía Loma Negra S.A., exponía que uno de los operarios, que había trabajado como foguín en la sección pedregullo y luego en la cuadrilla de descarga, desempeñándose siempre como peón industrial, desde el 1 de diciembre de 1928, fecha en que ingresó a la fábrica Loma Negra S.A., fue despedido el 8 de enero de 1940 por insubordinación y mal comportamiento. ${ }^{11}$ Por su parte, el operario expresaba que había sido contratado como peón de trasporte, que se había desempeñado satisfactoriamente en la empresa durante 12 años, y como prueba de ello manifestaba el aumento del jornal en varias oportunidades. Acusaba al capataz de exigirles a los obreros esfuerzos imposibles y que ante la observación de dicho capataz y la respuesta del operario, que aseguraba haberla realizado en buenos términos, el superior replicó que lo haría echar. El operario afirmó lo siguiente: "no sé que razones y argumentos, inciertos en verdad, habrá dado la superioridad, pero el día 8 de enero fui despedido y sin darme explicaciones, a pesar de haber sido entrevistado por otro superior." Por tal motivo, el trabajador exigió dos meses de indemnización por falta de pre-aviso. El caso señalado es uno de los tantos donde aparece la palabra de los obreros expresando la idea que ante los reclamos presentados a sus superiores, las respuestas de ellos eran siempre las mismas: "que los harían echar."12

En otro caso, el conflicto entre dos empleados de la empresa Sierras Bayas, se inició por un intercambio de palabras, motivado por cuestiones de trabajo entre un obrero y el

11 Archivo Histórico Municipal de Olavarría (en adelante AHMO), Exp.: Año 1940. Núm. 10750, foja 1.

12 AHMO, Exp.: Año 1940. Núm. 10750, foja 6.

\section{4}


segundo capataz de cantera, ambos se trabaron en lucha, hallándose el primero armado con una llave de hierro, resultando el último con heridas cortantes en el ojo derecho, clavícula del mismo lado y región frontal, siendo separados por varios compañeros de trabajo que se hallaban en las proximidades. ${ }^{13} \mathrm{Al}$ expresar su declaración, el capataz informó que cuando se dirigía a su trabajo en la cantera y en circunstancias en que el obrero manejaba una máquina perforadora, el capataz mandó a otro ayudante que fuera a abrir el aire de la mencionada máquina a fin de acelerar el trabajo, y que como veía que su orden no era obedecida exclamó que lo que no se realizara ese día, se haría al día siguiente. Luego de un intercambio de palabras, el obrero armado de una llave de hierro, lo agredió con un golpe en la cabeza, provocándole una fuerte lesión en el ojo derecho, golpe que no habría llegado con la violencia con la que había sido dirigida porque el capataz alcanzó a frenarlo con el brazo. Enseguida se tomaron en lucha y varios obreros intervinieron con la intención de separarlos. En las declaraciones del obrero que participó del conflicto, como los demás que fueron testigos de la pelea y que trabajaban en la misma sección, se hacía referencia a los malos tratos y exigencias del capataz hacia los obreros de la cantera, motivo por el cual se ganaba la antipatía de los trabajadores. ${ }^{14}$

Las discusiones ocasionales en el trabajo, se relacionaban con las formas de producción, o con las órdenes de los capataces que no eran obedecidas. Los testimonios de los obreros coincidían en atribuir lo ocurrido al fuerte temperamento de aquellos, ya que aseguraban que frecuentemente los reprendían aunque no estuvieran bajo su autoridad, como vimos en un caso antes analizado donde el trabajador pertenecía a una sección distinta a la del capataz involucrado. ${ }^{15}$ Es en la descripción de las peleas que enfrentaban a los obreros con sus capataces, donde podemos ver simbolizada la idea de delimitación de un cierto orden. En la imagen que se construye y en el discurso que se difunde, la figura del capataz aparece como la persona encargada de sancionar y principalmente de vigilar a los trabajadores.

Los problemas que ocurrían en el proceso de producción, ya sea por desperfectos en las maquinarias, falta de insumos, entre otros inconvenientes, eran generalmente los motivos por los que se desencadenaban los enfrentamientos entre los empleados de la empresa. Es decir, cuando aparecían problemas en el proceso de producción, generalmente ocasionaban fuertes altercados entre los mismos obreros o entre éstos y sus superiores. Otro ejemplo de ello es un incidente laboral, que se expresó mediante la disputa entre dos empleados de la Compañía Industrial Argentina Loma Negra S.A., donde se habrían tomado a golpes de puño por cuestiones de trabajo produciéndose lesiones en el rostro. Los relatos de los trabajadores que se vieron involucrados en este conflicto aseguraban que, en circunstancias en las que se encontraban trabajando, se detuvo la máquina rompedora, que desde hacía unos días

13 AHMO, Exp.: Año 1941. Núm. 3271, foja 6.

14 AHMO, Exp.: Año 1941. Núm. 3271, foja 9.

15 AHMO, Exp.: Año 1941. Núm. 3271, foja 13. 
venía funcionando mal, inconveniente que había sido comunicado al capataz general y que en el momento que uno de los obreros salía de la máquina, desatorándola para ponerla en marcha nuevamente, se hizo presente en el lugar el capataz al que el obrero le dijo "¿vio que la máquina nuevamente se volvió a parar?" a lo que el capataz de forma prepotente respondió: "¿Y a usted qué carajo le importa?" Agregando que si la máquina andaba mal el obrero no tenía por qué preocuparse ni ocuparse ya que el técnico se encargaría de ello. Como consecuencia de esta respuesta, y dado que supuestamente no era la primera vez que le respondía de esa forma, el operario le aplicó algunos golpes de puños, produciéndole lesiones en la cara. ${ }^{16}$ En los testimonios referidos a la reyerta, los obreros manifestaron que ese capataz con frecuencia tenía incidencias con los trabajadores de la cantera por su forma improcedente de tratar al personal, ya que tendría por costumbre hacerlo de manera insolente y prepotente, lo que motivaría la reacción de los mismos. ${ }^{17} \mathrm{El}$ modo despótico con que los capataces se dirigían a los obreros era lo que más molestaba a los trabajadores, ya que ellos se preocupaban por el funcionamiento de las maquinarias, mientras los capataces desestimaban esa preocupación.

En otra ocasión, en una de las canteras dedicadas a la producción de cal y cemento de la ciudad de Olavarría, un obrero y su capataz se enfrentaron y agredieron físicamente luego de una discusión iniciada por cuestiones laborales. El operario aseguraba que, mientras se encontraba agachado engrasando el engranaje del malacate que tiraba las vagonetas a la cantera de piedra de granito, su superior se acercó y de manera prepotente le pidió que dejara de realizar esa actividad, ya que llamaría a otra persona que supiera hacerla como correspondía. El operario ante esta agresión verbal, atacó a golpes a su capataz con la herramienta que en ese momento tenía en su mano. ${ }^{18}$

A su vez, un trabajador y su superior de la empresa Sierras Bayas S.A., se agredieron físicamente mientras se encontraban en sus lugares de trabajo. Al momento de declarar el capataz afirmó que mientras se encontraban trabajando en la fábrica de cemento portland, le indicó al operario que fuera a comunicar una novedad que había surgido en la maquinaria que estaba a su cargo, a lo que el operario se negó y ante su insistencia, el obrero le respondió con golpes de puño. ${ }^{19}$ Otro caso, también aparece en la empresa Sierras Bayas: un conflicto ocurrido entre un operario y su superior en la sección cantera. El capataz declaró que, estando el tractor a cargo del operario, le pidió si podía ir a buscar unas herramientas que necesitaba, orden que su superior supuestamente ya le había dado con anterioridad. El operario se negó y seguidamente le aplicó un golpe de puño en la cara. ${ }^{20}$

16 AHMO, Exp.: Año 1952. Núm. 161, foja 9.

17 AHMO, Exp.: Año 1952. Núm. 161, foja 11.

18 AHMO, Exp.: Año 1943. Núm. 1102, foja 5.

19 AHMO, Exp.: Año 1945. Núm. 196, foja 1.

20 AHMO, Exp.: Año 1944. Núm. 1012, foja 6. 
En otra oportunidad, en la sección de secadero de la empresa Sierras Bayas, un obrero le reclamó a su capataz que se le acreditara una hora de trabajo por estar realizando su actividad en una zona considerada insalubre debido al calor agobiante del secadero. La respuesta de su superior fue que no era algo que a él le correspondiera hacer, que no tenía órdenes de acreditar horas de trabajo en dicho de lugar de tareas y que debía dirigirse al capataz general con tales reclamos. Ante esta respuesta el obrero comenzó a insultarlo y a decirle que era un alcahuete, por lo que ante este acto considerado de indisciplina el capataz respondió que en lo sucesivo no trabajaría más a sus órdenes, decidiéndole que se dirigiera a la oficina de administración de la Compañía. El obrero enfurecido se acercó para pegarle y provocó la caída del capataz quien al retroceder, tropezó con una carretilla y al levantarse fue atacado por el operario provocándole lesiones en el rostro. ${ }^{21}$

Tal como afirma Montes Cató, más allá de "las formas ensayadas por el Capital para articular técnicas disciplinarias que permitan elaborar un determinado orden en los espacios laborales y que a su vez, permitan a las direcciones de las empresas controlar la producción y reproducción del proceso productivo, no es menos cierto que ello depende en gran medida de las respuestas e iniciativas de los trabajadores..."22 Los conflictos laborales que hemos rescatado y que se registran en los expedientes judiciales, hacen referencia a las peleas producidas entre los operarios de las empresas cementeras y sus superiores, quienes ocupaban diferentes cargos jerárquicos en la empresa. Pero también aparecen enfrentamientos, discusiones y peleas que finalizaban en fuertes agresiones físicas entre los mismos operarios, mientras se encontraban en sus puestos de trabajo. Si bien el tipo de conflictividad más común es la que se produce entre los trabajadores y la gerencia, por lo que estaríamos hablando de conflicto laboral cuando se trata de relaciones entre trabajadores y empleadores, creemos que la referencia al concepto de malestares entre trabajadores representa a los diversos tipos que pueden adoptar las tensiones entre los trabajadores, que más bien se relacionan con diferentes conductas de los mismos. ${ }^{23}$

Uno de los casos analizados, es el ocurrido en el interior de la fábrica de Cemento Portland Sierras Bayas, donde por cuestiones del momento dos obreros se tomaron a golpes de puño, en la sección de taller mecánico, provocándose ambos lesiones leves. ${ }^{24}$ El motivo de este conflicto se debió a que uno de los obreros se negó a prestarle a su compañero las herramientas que necesitaba para reparar una máquina del sector. En otro caso, se presenta

21 AHMO, Exp.: Año 1959. Núm.133, foja 2.

22 MONTES CATÓ, Juan, "Dominación en los espacios de trabajo y formas de expresión del conflicto: las nuevas generaciones de trabajadores frente a las políticas manageriales.", ponencia presentada en XXVI Congreso de la Asociación Latinoamericana de Sociología, Guadalajara, México 13 y 18 de agosto de 2007, p. 13.

23 Ídem, p. 5

24 AHMO, Exp.: Año 1952. Núm. 165, foja 2. 
el enfrentamiento entre dos hombres en el interior de la embolsadora de la empresa Loma Negra S.A., que se desencadenó por cuestiones de trabajo, no quedando bien claro cuál fue el motivo principal del conflicto, donde los empleados terminaron agrediéndose físicamente. ${ }^{25}$

En otro episodio, el enfrentamiento se dio en la sección usina, de la empresa Sierras Bayas, y en esta ocasión dos trabajadores, tuvieron un altercado cuando uno de ellos ofendió de palabra al otro diciéndole que si no sabía trabajar que fuera a aprender, y a raíz de ello se inició la discusión que finalizo con una pelea. Uno de los testimonios señalaba que dado que en su sección se encontraba la boca de presión que alimentaba las calderas, le pidió a su compañero que le diera más presión a la bomba ya que la caldera había quedado casi sin agua. Dado que aparentemente existía la orden de elevar la presión hasta un máximo de 250 a 255 libras, el trabajador interpelado le manifestó a su compañero que no cedería a su pedido de elevarla a 270 como le solicitaba. Ante esta respuesta quien hacía el pedido comenzó a insultarlo, reprochándole su actitud, tildándolo de carnero y rufián, entre otras cosas. ${ }^{26}$

Tal como afirma John Womack resulta interesante saber que hacían los trabajadores en el lugar de trabajo para entender cómo los afectaba en su vida diaria fuera del mismo. Más allá de tener presente las relaciones laborales de trabajo, es fundamental tener en cuenta los vínculos entre los trabajadores en el lugar de labor, mientras trabajan. ${ }^{27}$ Comprender la conducta de los trabajadores en las fábricas, el comportamiento de los mismos, las negociaciones, nos lleva a comprender el significado social que adquieren por ejemplo los conflictos, en relación a las formas de control impuestas en el lugar de trabajo. Las reacciones violentas de los trabajadores, que caracterizan a todos los enfrentamientos descriptos, parecerían una respuesta a un tipo de actitud patronal basada en la vigilancia directa y despótica impuesta por lo capataces.

Creemos que resulta fundamental rescatar las cuestiones subjetivas, la socialización y la formación cultural, ya que nos permite comprender de qué manera adquieren un determinado sentido, ciertas conductas obreras. El alto grado de violencia con el que se llevaban adelante las peleas entre los trabajadores en las diferentes secciones de las empresas, y como parte de las relaciones laborales, aparece como un aspecto generalizado y que nos permite plantear otras cuestiones que se vinculan directamente con la disciplina que los dueños buscaban imponer en sus empresas. De ahí podemos plantear la relación con el código de conducta, tanto formal como informal, que en este contexto establecían las empresas cementeras, y la necesaria aplicación de dicha variable en estos espacio donde no era precisamente la armonía la característica fundamental que regía de las relaciones laborales. El reglamento para el personal obrero de las empresas, aclaraba que no se permitiría la entrada al trabajo en estado

25 AHMO, Exp.: Año 1959. Núm.104, foja 1.

26 AHMO, Exp.: Año 1959. Núm.134, foja 6.

27 WOMACK, John: Posición estratégica y fuerza obrera. Hacia una nueva historia de los movimientos obreros, Fondo de Cultura Económica, México, 2007, p. 17.

\section{8}


de ebriedad y sería suspendido por el tiempo que fije la administración todo operario que se haga cargo de sus tareas en tal estado. En caso de reincidencia, se procedería a separarlo del establecimiento. ${ }^{28} \mathrm{El} \mathrm{mismo} \mathrm{reglamento} \mathrm{hacía} \mathrm{referencia} \mathrm{a} \mathrm{que} \mathrm{el} \mathrm{personal} \mathrm{debería} \mathrm{observar}$ estrictamente las órdenes que recibiera de sus respectivos superiores, en forma verbal, por intermedio de avisos u otros medios de comunicación; guardar el orden y disciplina en todo momento, teniendo asimismo presente que tanto su conducta en el trabajo como la que se observara en la vida dentro del estableciendo sería tenida en cuenta por la compañía, para la evaluación del trabajador. Lo que se pretendía obtener de los trabajadores era una conducta laboral, que se adecuara a los objetivos estratégicos de las empresas. Por ello se diseñaban y ejecutaban una serie de dispositivos de diferente intensidad y dimensión, caracterizados por un tipo de tecnología específica, por el diseño organizacional, por políticas de gestión de mano de obra y por la adecuación del sistema normativo. ${ }^{29}$

Sobre el proceso de producción y la importancia del conocimiento de tal actividad, debemos tener presente que en estas empresas, el oficio se aprendía por medio de la práctica, instrucción ejercida por los obreros que ya contaban con la experiencia necesaria para desempeñarse en cada sección de la fábrica. La entrada en ella a temprana edad, a los 14 años, permitía al trabajador ir incorporando los saberes profesionales necesarios. La formación de la mano de obra era un elemento relevante para la empresa, proceso en el cual el aprendiz cumplía un rol central. En la formación de la mano de obra, el aprendiz cumplió un rol importante, ya que se trataba de un sistema de aprendizaje para menores de la clase obrera. Entre nuestros entrevistados, el aprendizaje se concretaba mediante la enseñanza de otros trabajadores dentro de la empresa y aparece como el primer escalón en la obtención del saber del oficio. Su importancia radicaba en asegurar no solo la formación calificada de obreros, sino también la permanencia de estos en la empresa. Así, el aprendiz, iba incorporando hábitos de trabajo, acumulaba experiencia y conocimiento desde temprana edad. ${ }^{30}$

Por un lado, era un aprendizaje para realizar correctamente el trabajo. Por otro lado, lograba cubrir otros aspectos "del comportamiento extra fabril, de las relaciones humanas y de los valores morales. En ese sentido, la educación formal no aparece como la más sobresaliente, sino que es el 'aprendizaje informal' el que se destaca con mayor énfasis" ${ }^{31}$, particularmente como formador de una cultura del trabajo. La experiencia de los trabajadores se originaba en el aprendizaje del oficio y de ciertos valores éticos en su relación con los

28 Reglamento para el Personal Obrero de Calera Avellaneda S.A. Aprobado por el departamento de Trabajo de la Provincia de buenos Aires el día 2 de julio de 1940.

29 MONTES CATO, Juan, “Dominación en los espacios de trabajo...” Op. Cit., pág. 6.

30 Testimonio un ex obrero de Calera Avellaneda S.A., Olavarría, 06/02/2007.

31 SIMONASSI, Silvia, "De cómo los patrones parecían padres. Una mirada histórica a los menores aprendices de las fábricas metalúrgicas del Gran Rosario", en Revista de la Escuela de Antropología. Rosario, noviembre 2000, V. 5, p. 37. 
otros y con el propio trabajo. La ambigüedad que planteaba la enseñanza en la formación del oficio, quedaba expresada de la siguiente forma: por un lado, aseguraba la reproducción de la mano de obra calificada pero, al mismo tiempo, se encargaba de la transmisión de diferentes saberes y sentimientos, que contribuyeron a la conformación de una identidad obrera y a la incorporación de estos códigos informales que cumplían un rol central como parte de las relaciones laborales, que se veían quebrantados mediante los conflictos ocurridos en el ámbito laboral.

Por otra parte, en las cuestiones que se vinculan directamente con el proceso de producción, podemos inferir la fuerte presencia e intervención de los trabajadores en dicho proceso. Aquí logramos establecer una relación directa entre la información que nos brindan las fuentes, contraponiendo y estableciendo un nexo entre lo que nos dicen los expedientes judiciales donde se manifiestan los conflictos entre los trabajadores y sus superiores, y por otra parte lo que nos dice el reglamento aplicado sobre el personal de las empresas. Sabemos los problemas que ocasionaban entre los trabajadores la falta de acuerdo en relación a las tareas que cada uno de ellos debía realizar según la sección que le correspondiera, y que muchas veces ese inconveniente era el disparador de los enfrentamientos. El hecho de no coincidir en cómo realizar una determinada tarea llevaba a discusiones y peleas entre los trabajadores y con sus superiores. La necesidad de aplicar un régimen disciplinario dentro de estas empresas, aparece demostrado en el reglamento de trabajo, donde se delimitaban y especificaban cuestiones que se relacionan con las sanciones que se aplicarían a los obreros en caso de violentar las normas de conductas establecidas por dicho reglamento.

Los trabajadores intervenían directamente en el proceso de producción, y tal como lo establecía el reglamento, eran responsables de la conservación y buen funcionamiento de las máquinas, herramientas y útiles que recibían, pertenecientes a la empresa, debiendo tenerlas bajo su custodia y en condiciones de presentar inventario en cualquier momento. Además, todo operario debía colaborar con sus superiores y demás personal, comunicando a aquellos toda iniciativa de perfeccionamiento de los métodos de trabajo y operaciones en general, como así mismo informar de los desperfectos, irregularidades, etc. que impidieran la obtención del máximo rendimiento de aquellos, con la supuesta seguridad que al velar por los intereses de la empresa, lo harían por los suyos propios. ${ }^{32}$

Mantener un clima cordial que rigiera las relaciones laborales era una premisa fundamental propuesta por estas empresas y ello queda expresado en los contenidos del reglamente analizado. Por otra parte, los fuertes conflictos que se presentaban entre los trabajadores y con sus superiores, nos demuestran que existían motivos claros por los que la empresa se preocupaba para poder establecer una determinada disciplina, debido a que la falta de la misma producía problemas que incidían negativamente en la producción de cemento.

32 Reglamento para el Personal Obrero de Calera Avellaneda S.A. Aprobado por el departamento de Trabajo de la Provincia de Buenos Aires el día 2 de julio de 1940. 
En los testimonios de los capataces, en relación a los conflictos ocurridos, aparece la idea de la importancia y el significado del orden disciplinario para la realidad cotidiana de las empresas. Expresaban permanentemente el argumento que afirmaba que muchas veces sus órdenes no eran obedecidas por los operarios y ante sus insistencias, las respuestas de los trabajadores se manifestaban siempre por medio de la violencia. ${ }^{33}$

\section{La organización sindical}

Hasta la consolidación del sindicato que nucleaba a los representantes de los trabajadores de las empresas del cemento, los problemas se solucionaban, en muchos casos, estableciendo un diálogo con los patrones a quienes se les expresaban los reclamos. Es decir, esa relación individual entre el trabajador y el patrón, o el representante del patrón, era el principal vínculo hasta la aparición en escena de la figura del sindicato como símbolo de la representación del trabajador del cemento. De todos modos, la "buena y cercana relación" que el sindicato demostró tener con los dueños de las empresas, habría generado en gran parte de los trabajadores cierta desconfianza y una falta de reconocimiento hacia la organización sindical.

Partiendo de la conformación del sindicato que representaba a los trabajadores de las empresas cementeras de la ciudad de Olavarría, debemos destacar que se inició cuando un grupo de empleados de varias empresas fundaron, el 29 de octubre de 1945, el Sindicato Obrero de la Industria de la Cal, Cemento y Afines (SOICCA), dando lugar a un nuevo actor social de mucha actuación en los años siguientes, no sólo en lo relativo a la discusión de condiciones de trabajo sino también en lo que se refiere a difundir la organización obrera en la región. ${ }^{34}$ "En 1947 se constituyó el Sindicato Único de Obreros del Cemento, Cal y Anexos de Olavarría, que incluía a todos los sindicatos de fábrica de la región y en 1953 se produjo la unificación nacional bajo AOMA. Al año siguiente se discutió el primer Convenio Colectivo de Trabajo y se decretó la primera huelga cuando las negociaciones se trabaron". ${ }^{35}$

Debemos señalar también, necesariamente y para una completa interpretación, que es en el año 1956 cuando se inició en la sociedad argentina la intervención de los sindicatos peronistas y el período conocido como la resistencia peronista. El contexto nacional estaba caracterizado por un estricto control a las actividades sindicales, que pasaron a ser supervisadas por un interventor, por lo tanto las actividades e iniciativas quedaron limitadas a las decisiones de un agente externo. La represión sobre los dirigentes y activistas peronistas durante la Revolución Libertadora fue uno de los rasgos más característicos durante este período. Tal como afirma Daniel James, el "fenómeno de la resistencia ofrecida por las bases,

33 AHMO, Exp.: Año 1941. Núm. 3528, foja 4.

34 Suplemento especial, Aniversario número 50 de la creación del sindicato AOMA, seccional Calera Avellaneda. Diario El Popular, sábado 28 de Octubre de 1995.

35 NEIBURG, Federico, Fábrica y Villa Obrera..., Op. Cit. p. 67. 
que duró subyacente durante todo ese período, agregó una dimensión vital al proceso entero de negociación y compromiso entre el gobierno y los líderes sindicales". "Concretamente, la política del nuevo gobierno con la clase trabajadora siguió tres líneas principales. Ante todo, se intentó proscribir legalmente un estrato entero de dirigentes sindicales peronistas para apartarlos de toda futura actividad. Esto concordó con la nueva intervención de la $\mathrm{CGT}^{37}$ y la designación de supervisores militares en todos sus sindicatos, lo que habría de preparar el camino para la creación de 'bases democráticas en los sindicatos, y la elección de dirigentes con autoridad moral. En segundo término, se llevó a cabo una persistente política de represión e intimidación del sindicalismo y sus activistas en el plano más popular y básico. Finalmente, hubo un esfuerzo concertado entre el gobierno y los empleadores en torno del tema de la productividad y la racionalización del trabajo, proceso que marchó de la mano con un intento de frenar los salarios y reestructurar el funcionamiento del sistema de negociaciones colectivas". "Como reacción contra esas políticas y contra lo que significaban concretamente en términos de peores condiciones de trabajo y debilitamiento de la organización gremial en la fábrica y en el nivel nacional, importantes sectores de la clase trabajadora se embarcaron en la larga lucha defensiva que llegaría a ser conocida, en la cultura de la clase obrera peronista, como 'la Resistencia'. En parte constituyó una respuesta defensiva a la franca represión y al hostigamiento de los trabajadores en el sitio de trabajo. Casi todo operario que pudiera ser conceptuado un "perturbador" era vulnerable y estaba expuesto a represalias al capricho del sector patronal. ${ }^{39}$

El inicio de la resistencia peronista, aparece como un punto de inflexión en la historia del sindicalismo tanto nacional como local, y es en este punto donde podemos ver materializadas las cuestiones sindicales relacionadas con la negociación y la resistencia. Tal como mencionábamos, uno de los rasgos que caracterizó el funcionamiento del sindicato en estas empresas, fue la de negociación permanente en lugar de un enfrentamiento directo. Tal como nos cuenta un ex representante sindical de la empresa Calera Avellaneda S.A.:

Desde el sindicato siempre se optó por el diálogo ya que creemos que llevar a la gente al paro es negativo, esto te lleva a una etapa conflictiva porque después comienzan los paros seguidos, y se termina usando como expresión permanente... ${ }^{40} \ldots$ La parte

36 JAMES, Daniel, Resistencia e Integración. El peronismo y la clase trabajadora argentina, 19461976, Siglo Veintiuno editores Argentina S.A., Buenos Aires, 2005, p. 80.

37 Confederación General de Trabajo.

38 Ídem, pp. 82-83.

39 Ídem, p. 91.

40 Testimonio del ex secretario General del Sindicato AOMA, seccional Calera Avellaneda, Armando Domínguez, Olavarría, 07/09/2005. 
sindical es la que hace los arreglos internos, que te hago huelga hoy, que otro día no, eso lo maneja más el sindicato con la empresa, no los trabajadores... ${ }^{41}$

Los testimonios de los trabajadores muestran una falta de confianza hacia el sindicato y remarcan que, durante el período estudiado, su función era prescindible, ya que si ocurría algún tipo de inconveniente se podía recurrir a un encuentro directo con el patrón y eso garantizaba una rápida solución. Por otra parte, en los relatos de los ex trabajadores, aparecen también aquellos testimonios que reflejan el grado de disciplina con el que se trabajaba en las empresas y las consecuencias que podía tener presentar un reclamo ante la patronal. Estos relatos, estarían señalando que, más que un fuerte control, este comportamiento se relacionaría con un determinado grado de disciplina aplicada en el ámbito laboral, muy alejado de la posibilidad de elección del trabajador. Quienes reclamaban o decidían hacer una huelga como parte de algún reclamo, sabían que se exponían no sólo a quedarse sin su fuente de trabajo, sino también a perder la casa que la empresa le había prestado si integraba la villa obrera, y el resto de los beneficios sociales a los que, como parte de las estrategias empresariales desplegadas, el obrero accedía. "En la idea de dependencia también está presente la búsqueda consciente de los beneficios: dar algo para recibir algo a cambio. Los trabajadores maximizaban los beneficios, negociaban con el patrón, pero esto no derivaba en una simple relación de servilismo, aunque en algunos casos se creara un vínculo de dependencia. Se construía una representación ambigua de servilismo, pero también de negociación permanente, donde la lealtad y la sumisión se daban a cambio de más beneficios". ${ }^{42}$

En relación a los conflictos ocurridos, visualizamos en las empresas observadas una permanente negociación, concepto que despliega un mismo contenido y sentido como parte de esta relación laboral donde, por un lado, aparecen trabajadores que aceptaban las reglas del juego que imponía la relación paternalista y, por otro, un patrón que en cierta medida y en determinados momentos también debía ceder a cambio de mantener esa lealtad. Las dos partes intercambiaban con la pretensión de obtener más ganancias que las esperadas, los propios actores definían las oportunidades alternativas, los márgenes de la libertad y las coacciones de la acción. Siguiendo la idea planteada por Michael Burawoy en su estudio centrado en los procesos de trabajo, podemos destacar entonces al "conflicto como parte necesaria de las negociaciones, más que un conflicto en sí, donde los elementos estarían actuando conjuntamente con lo que se produciría, según el autor, un desplazamiento del conflicto jerárquico en las relaciones de producción por un conflicto lateral entre los trabajadores. Creemos que el análisis de la negociación también puede verse como una cierta estructura de orden jerárquico, donde por ejemplo es posible identificar primero, la negociación entre

41 Testimonio de un ex obrero de Calera Avellaneda y ex vecino de la villa obrera von Bernard: Alberto Soraisz, Olavarría, 06/02/2007.

42 NEIBURG, Federico, Fábrica y Villa Obrera..., Op. Cit., p. 173. 
el Estado y los empresarios del cemento, luego éstos últimos con la organización sindical y finalmente, el sindicato con los trabajadores". ${ }^{43}$

Otro de los elemento centrales que quisiéramos destacar se relaciona con la cuestión de los sabotajes en las empresa. Antes de interiorizarnos en algunos casos específicos, quisiéramos destacar y tener presente que los actos de sabotaje pueden expresar una forma de resistencia algunas veces y en otras ocasiones, no. Tal como afirma Juan Montes Cató retomando los planteos de Edward y Scullion es necesario tener presente "en qué medida estos episodios pueden afectar la negociación del esfuerzo en un espacio laboral específico y de qué manera los participantes perciben el sabotaje, ausencia injustificada, etc. como una expresión del conflicto, poniéndose así en juego dos órdenes de cosas: el contexto donde se despliegan las relaciones de trabajo y por otra parte, los significados que poseen para los trabajadores y empresarios. Es decir, el comportamiento, lo visible, no puede explicarse a través del estudio de lo manifiesto sino que adquiere sentido a través del análisis del contexto social en que se produce y los significados sociales que posee para los sujetos participantes". ${ }^{44}$ Se considera el nivel del comportamiento concreto, precisamente, "qué formas de comportamiento son viables, hasta qué punto reflejan el conflicto y hasta qué punto representan formas de adaptación a la situación motivadas por el carácter de las relaciones laborales en el centro de trabajo en las que se producen". 45 "Edwards y Scullion proponen en efecto, tres categorías de conflicto. En función del alcance de este marco analítico, los autores se preguntan 'por qué ocurre... [el sabotaje]... en algunas situaciones y no en otras y qué significado tiene ese comportamiento dentro de un proceso de trabajo concreto" ". ${ }^{46}$ "En otras palabras, es un mecanismo para preguntar cómo están expresadas de hecho en la acción las contradicciones subyacentes, no es una afirmación de que exista necesariamente relación alguna (Edwards y Scullion, 1987: 28)"'47.

Vemos también como el sindicato servirá para mediar ante alguno de los despidos que la empresa realizaba sin justa causa, como el siguiente caso....

Se reincorpora a los cinco obreros de la empresa Loma Negra S.A. que habían sido despedidos por 'falta de confianza.' La reincorporación se funda en el hecho puro y simple que lo llamado por la patronal "falta de confianza" no es suficiente causa para

43 BURAWOY, Michael, El consentimiento en la producción. Los cambios del proceso productivo en el capitalismo monopolista, Madrid, Ministerio de Trabajo y Seguridad Social, 1989, pp. 123-128. 44 MONTES CATÓ, Juan, "Reflexiones teóricas en torno al estudio del conflicto laboral. Los procesos de construcción social de la resistencia" en Trabajo y Sociedad Indagaciones sobre el trabajo, la cultura y las prácticas políticas en sociedades segmentadas, $N^{\circ}$ 9, V. IX, Invierno 2007, Santiago del Estero, Argentina p. 14.

45 Ídem, p. 15.

46 Ídem, p. 16.

47 Íbídem. 
dejar a los trabajadores sin el elemento vital de su sustento... La sospecha no puede alcanzar para el despido, ya que por esa vía se llegaría a verdaderas arbitrariedades e intentos de eliminación de quienes simplemente resulten molestos a determinados intereses patronales. ${ }^{48}$

Dentro de las juntas interventoras también participaban obreros y ello es interesante dado que si bien el sindicato se encontraba intervenido y limitado en sus actividades, no aparecía una actitud antiobrera, por el contrario estaba presente la posibilidad de continuar defendiendo los intereses de sus compañeros. Analizado en el contexto nacional, es donde observamos el comienzo de un proceso de movilización y conflictividad muy importante, que fortaleció a los sindicatos y reafirmó la presencia peronista en los mismos. Tal como mencionábamos, las actividades que los representantes del sindicato realizaban en este contexto se veían limitadas por un intenso control ejercido en todos los ámbitos pero principalmente en las empresas cementeras. Debemos tener nuevamente presente la situación del contexto nacional en 1956, dado que "para fines de septiembre de ese año, los locales de los sindicatos de gráficos, ferroviarios, bancarios, petroleros y trabajadores de la carne y del vestido habían sido abandonados por los peronistas frente a los ataques de grupos antiperonistas armados. Esos grupos, conocidos como 'comandos civiles', consistían principalmente en activistas socialistas y radicales. Habían desempeñado un papel importante en la rebelión contra Perón y se consideraban como una milicia civil que serviría de garantía contra cualquier resurgimiento peronista. En ese carácter tendieron a recibir apoyo de sectores de las fuerzas armadas para los ataques a los locales sindicales", lo que llevó a la CGT a emitir "un comunicado donde se solicitaba al gobierno poner fin a la ocupación de algunos locales gremiales por gente armada y, al mismo tiempo, se reafirmaba el deseo de la CGT de que se celebraran elecciones democráticas lo antes posible". 49 "Desde un punto de vista inmediato, en octubre de 1955, se oponían a la inauguración de un proceso electoral sindical que casi seguramente confirmaría el dominio de los gremios, y por lo tanto de la CGT, por los peronistas. También los alarmaba el hecho de que no obstante las muchas renuncias de dirigentes peronistas y la iniciación del proceso electoral, los comicios terminaran por quedar bajo el control general de los peronistas. Esos temores fueron acentuados por la decisión gubernamental de instalar interventores designados por la CGT en sindicatos donde había un conflicto abierto entre peronistas y no peronistas. Los más afectados por esta política eran precisamente aquellos donde las fuerzas antiperonistas tenían mayor poder." ${ }^{" 50}$ Mirando nuevamente el plano nacional, las movilizaciones de activistas, peronistas y comunistas, aparecen con la intención de poner en funcionamiento la CGT

48 Diario Tribuna, Olavarría, martes 7 de agosto de 1956, p. 4.

49 JAMES, Daniel, Resistencia e Integración..., Op. Cit., p.p. 70-71.

50 Ídem, p. 72. 
y eso era lo que se expresaba también en Olavarría, ante la necesidad de reactivar en esa ciudad, la central obrera intervenida por el gobierno militar.

En cuanto a las dirigentes sindicales locales y sus prácticas, pude decirse que se fueron modificando y resultaba común escuchar mencionar la comparación frecuente entre "viejos" y "nuevos" líderes sindicales. Los primeros, eran aquellos que iniciaban su actividad de forma un tanto más autónoma, que si bien siempre estuvieron ligados e influenciados en cierta medida por la empresa, nacían con el impulso y la convicción de ser la nueva alternativa de representación del trabajador. Los segundos, los nuevos líderes sindicales, eran quienes estaban más bien relacionados con la clara y decisiva influencia de la empresa en cuanto a los límites y las formas de representar a los trabajadores. Nuestros entrevistados, no recuerdan conflictos importantes ocurridos en las empresas, ni la activa participación del sindicato en tales conflictos, otorgándole un rol más bien pasivo y conciliador. Prefieren no hablar del tema y aseguran que si pasaba algo enseguida se solucionaba, sin llegar a convertirse en un problema mayor. Pero como vimos en el punto que hablamos de la disciplina aplicable al ámbito de trabajo, las peleas que se daban entre los trabajadores y éstos mismos con sus capataces, nos muestran que realmente existían motivos claros para que los patrones se preocuparan por imponer una cierta disciplina.

\section{Reflexiones finales}

En la presente investigación nos propusimos analizar las relaciones laborales y sus efectos en el proceso de producción dentro de las compañías cementeras de la ciudad de Olavarría en el período 1940-1970. Para ello retomamos algunos expedientes judiciales, donde se registran los conflictos ocurridos en las empresas dentro del ámbito laboral, entre los obreros del cemento y sus superiores y entre los mismos operarios. El propósito de ello ha sido, por un lado, descubrir cuáles eran las pautas que regían los comportamientos de los trabajadores de las empresas cementeras durante este período y analizar la aplicación de una determinada disciplina; y por otro demostrar de que manera influenciaban las alteraciones de las relaciones laborales en el proceso de producción.

Siguiendo algunas de las interpretaciones de los trabajos de Edwards y Scullion ${ }^{51}$ tratamos de comprender la configuración del conflicto en los espacios de trabajo, al vincular aspectos del orden estructural y los comportamientos concretos, con el objetivo de visualizar las características y formas de las relaciones laborales en la producción cementera, enfatizando en los conflictos laborales que se expresaron en las agresiones a los capataces. En los expedientes judiciales encontramos representada la voz de aquellos trabajadores que formaban parte del proceso de producción y que de alguna u otro manera modificaban con su accionar las medidas tomadas por las empresas. Creemos que si bien las estrategias

51 EDWARDS, P. K. y SCULLION, Hugo, La organización social..., Op. Cit. 
empresariales moldeaban las relaciones laborales, la conductas de los propios trabajadores cumplieron un rol central, por lo que partiendo del origen de los conflicto dentro del proceso de producción, el mismo adquiere en estas empresas un significado particular, manifestándose en diferentes formas de conductas que resulta interesante poder rescatar.

También analizamos el rol que cumplió la organización sindical durante el período estudiado, dado que la forma tan directa que vinculaba al trabajador con su patrón, limitaba la presencia y el accionar del sindicato en estas empresas. Los trabajadores, en nuestras entrevistas, no le otorgaban al sindicato un lugar importante asegurando la ausencia de conflictos y que los problemas que aparecían se solucionaban hablando directamente con el patrón. A pesar de estas afirmaciones los conflictos ligados directamente al proceso de producción existieron y se expresaron permanentemente.

Recibido: 25/06/2013

Aceptado: 26/09/2013 